\title{
Nitriding of Fe-Cr Powdered Alloys by Ball Milling in Nitrogen Gas
}

\author{
Yoshikiyo OGINO, Kazuo NAMBA ${ }^{1)}$ and Tohru YAMASAKI
}

Department of Materials Science and Engineering, Faculty of Engineering, Himeji Institute of Technology, Shosha, Himeji, Hyogo-ken, 671-22 Japan. $\quad$ 1) Ishikawajima-Harima Heavy Industries Co., Ltd., Toyosu, Koto-ku, Tokyo, 135 Japan.

(Received on August 28, 1992; accepted in final form on December 18, 1992)

\begin{abstract}
Elemental iron and $\mathrm{Fe}_{100-X} \mathrm{Cr}_{X}(X=30,50$ and 70$)$ powder mixtures were milled in a vibrational ball mill under nitrogen atmosphere. Structural changes during milling, and thermal stabilities and magnetic properties of the milled powders were examined by means of $X$-ray analysis, HRTEM, DSC and Mössbauer spectroscopy. It was found that $\mathrm{Fe}-\mathrm{Cr}-\mathrm{N}$ powdered alloys with very high concentrations of nitrogen were able to be prepared by this technique. The structure of the powder particles was composed of nanometer-sized b.c.c grains supersaturated with nitrogen. With the nitrided $\mathrm{Fe}_{50} \mathrm{Cr}_{50}$ alloy, the grain size decreased to about $2 \mathrm{~nm}$ after alloying with about 12 at\% of nitrogen, and then X-ray diffraction took on an amorphous-like pattern. On annealing of the nitrided powders, a heat evolution due to the precipitation of chromium nitride was observed at temperatures around $850 \mathrm{~K}$. The Mössbauer analysis revealed that the nitrided $\mathrm{Fe}_{70} \mathrm{Cr}_{30}$ alloy had paramagnetic and ferromagnetic components. The nitrided $\mathrm{Fe}_{50} \mathrm{Cr}_{50}$ alloy became entirely paramagnetic after the reduction in grain size below about $5 \mathrm{~nm}$.
\end{abstract}

KEY WORDS: mechanical alloying; nitriding; iron-chromium-nitrogen alloys; magnetic properties.

\section{Introduction}

Mechanical alloying (MA) is a nonequilibrium process with which various unstable or metastable materials, such as supersaturated solid solutions, amorphous alloys and intermetallic compounds, can be prepared. This alloying technique has been applied to the alloying by solid state reactions between powdered elements. However, MA can also be applied to the alloying of gaseous elements by solid-gas reactions. ${ }^{1-4)}$ In particular, nitrogen can be alloyed up to high concentrations with nitride-forming transition metals and their alloys by ball-milling their powders in nitrogen gas. The nitrided powders have either nanocrystalline or amorphous structure. For instance, it has been shown that $\mathrm{Cr}-\mathrm{Cu}-\mathrm{N}$ amorphous alloys ${ }^{1)}$ and Fe-TiN nanocrystalline dual-phase alloys ${ }^{2)}$ can be prepared by ball-milling the powdered metals in nitrogen gas. The amorphous or nanocrystalline structure may favor the consolidation of the powders by sintering at low temperatures. Therefore, the nitriding by MA seems to be a promising process for producing high nitrogen steels or iron-nitride composite materials having very fine microstructures, which may be expected to exhibit improved or novel properties.

In the present study, this new nitriding technique was applied to the preparation of $\mathrm{Fe}-\mathrm{Cr}-\mathrm{N}$ powdered alloys, and structural changes of the powders during milling and subsequent annealing were examined in detail. An examination of the magnetic properties of the powdered alloys was also carried out in connection with the structural study.

\section{Experimental}

Elemental iron powder and $\mathrm{Fe}-\mathrm{Cr}$ mixtures of the powdered elements with compositions in the atomic proportions $\mathrm{Fe}_{100-X} \mathrm{Cr}_{X}(X=30,50$ and 70$)$ were milled in a vibrational ball mill. The purity was better than $99.8 \%$ for each of the powders. The vial of capacity $1.3 \times 10^{-3} \mathrm{~m}^{3}$ and balls of diameter $13 \mathrm{~mm}$ were made of SUS 304 stainless steel. The ball-to-powder weight ratio was $45: 1$. Ball milling was carried out in nitrogen and argon gases. The closed vial was evacuated after charging with the powder and subsequently nitrogen or argon gas was introduced into the vial. Ball milling was interrupted at predetermined intervals of time for sampling of the powders. After each sampling, the vial was filled with the gases in the same way as in the initial run. The temperature in the vial, which was measured at the end of milling by inserting a thermocouple, was about $373 \mathrm{~K}$. The nitrogen content of the powder was determined by a chemical analysis. The structure of the powder was examined by means of X-ray diffraction using $\mathrm{CuK} \alpha$ radiation, scanning electron microscopy (SEM), high resolution transmission electron microscopy (HRTEM) at an acceleration voltage of $200 \mathrm{kV}$, and Mössbauer spectroscopy using $14.4 \mathrm{keV}$ gamma radiation from a ${ }^{57} \mathrm{Co}$ source. The thermal stability of the nitrided powders was examined using differential scanning calorimetry (DSC). The DSC measurements were conducted in flowing argon gas as at a scanning rate of $0.33 \mathrm{~K} \mathrm{~s}^{-1}$. 


\section{Results}

\subsection{Structural Studies}

As shown in Fig. 1, where the nitrogen content of the powder was plotted as a function of milling time, large quantities of nitrogen were absorbed in the powders by milling in nitrogen gas. The amount of absorbed nitrogen increased with increase in the chromium content up to $50 \mathrm{at} \% \mathrm{Cr}$, and then slightly decreased at $70 \mathrm{at} \% \mathrm{Cr}$. The iron powder, too, absorbed about 4 at $\%$ of nitrogen after $300 \mathrm{~h}$ milling. However, the absorption in the iron powder might be due to the contamination with chromium from the vial and balls, which amounts to 0.92 at $\% \mathrm{Cr}$ after milling for $300 \mathrm{~h}$. Figure 2 shows X-ray diffraction patterns of the powders milled in nitrogen gas. The diffraction peaks from the b.c.c. phase broadened with increasing milling time and a broad maximum appeared after $100 \mathrm{~h}$ milling in the case of $\mathrm{Fe}_{50} \mathrm{Cr}_{50}$ and $\mathrm{Fe}_{30} \mathrm{Cr}_{70}$ powders. In order to examine the detailed structure of the high chromium alloys, the structure factor of the

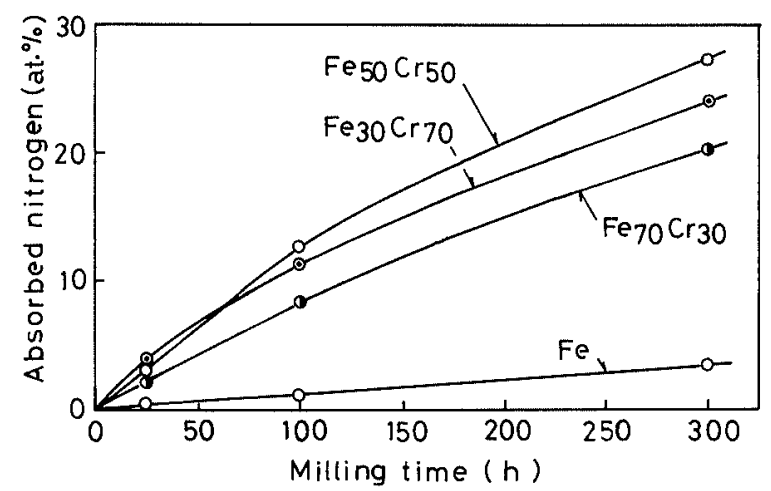

Fig. 1. Amounts of nitrogen absorbed by powders during milling in nitrogen gas plotted as a function of milling times.

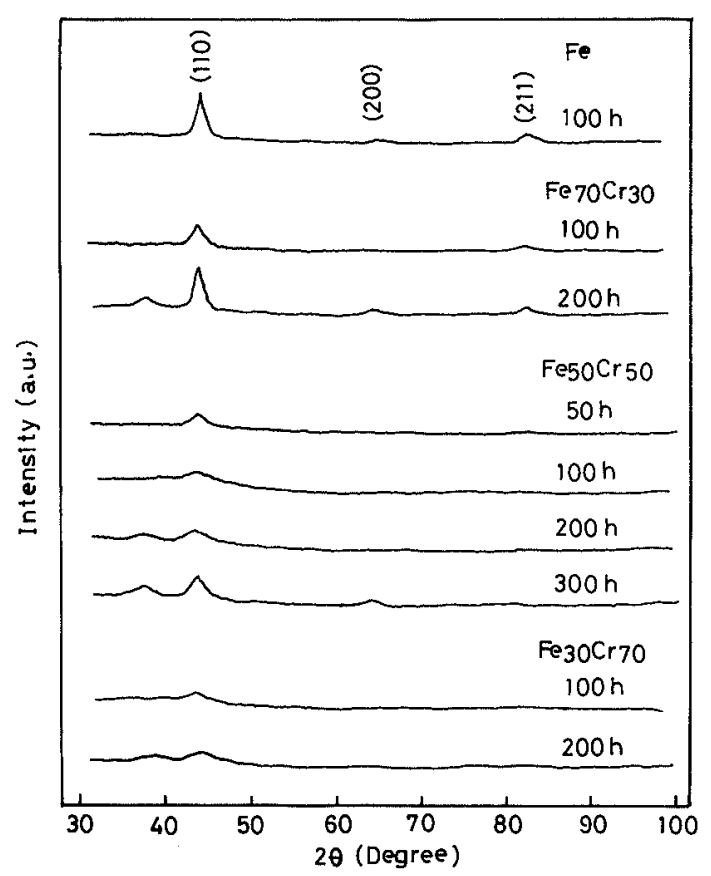

Fig. 2. X-ray diffraction patterns of iron, $\mathrm{Fe}_{70} \mathrm{Cr}_{30}, \mathrm{Fe}_{50} \mathrm{Cr}_{50}$ and $\mathrm{Fe}_{30} \mathrm{Cr}_{70}$ powders milled for several hours in nitrogen gas.
$\mathrm{Fe}_{50} \mathrm{Cr}_{50}$ powders milled for $50-200 \mathrm{~h}$ in nitrogen gas was calculated. As shown in Fig. 3, most of the crystalline peaks disappeared after milling for $100 \mathrm{~h}$, when about 12 at $\%$ of nitrogen had been absorbed, and instead of them an amorphous-like pattern appeared. On further milling, b.c.c. peaks and other extra peaks appeared, which were presumed to be due to the precipitation of chromium nitride $\mathrm{Cr}_{2} \mathrm{~N}$. The peak appeared at $2 \theta=37^{\circ}$ in the X-ray patterns (Fig. 2) is thus ascribed to diffraction from the nitride.

Grain sizes in the powder particles milled in nitrogen and argon gases were roughly estimated by applying the Scherrer formula to the (110) peaks and the broad maximum in the X-ray patterns after correcting for

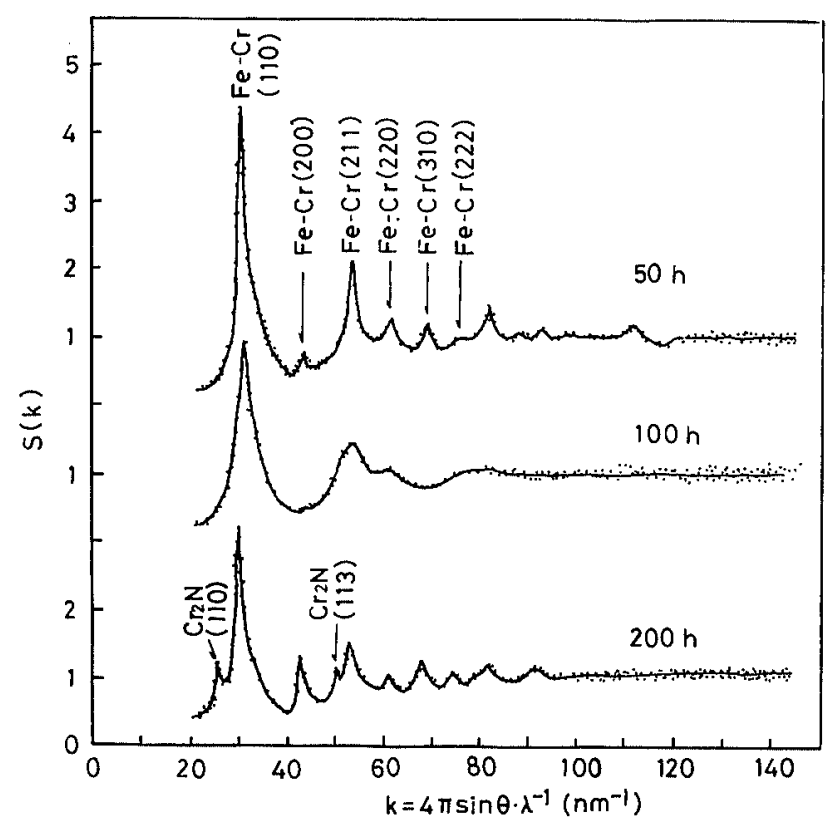

Fig. 3. Structure factors of $\mathrm{Fe}_{50} \mathrm{Cr}_{50}$ powders milled for several hours in nitrogen gas.

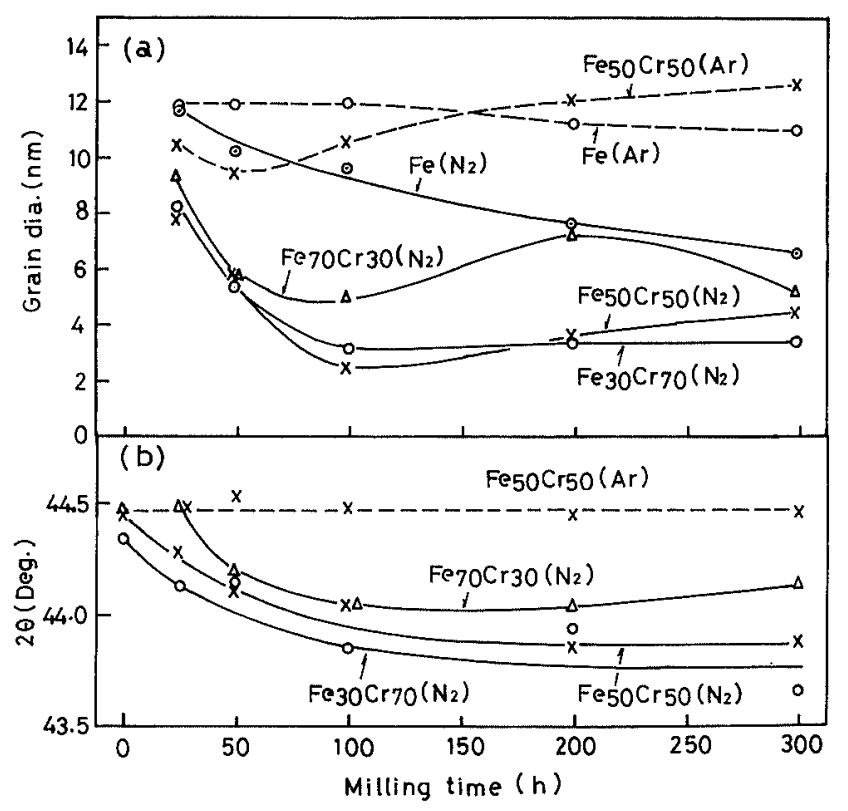

Fig. 4. (a) Grain sizes and (b) $2 \theta$ values of b.c.c. (110) reflections and broad maximum of amorphous phase in powders milled in nitrogen and argon gases, plotted as functions of milling times. 
instrument broadening. As shown in Fig. 4(a), grain refinement occurred much more significantly by milling in nitrogen gas than it was the case with argon gas. The grain sizes of $\mathrm{Fe}-\mathrm{Cr}$ powders milled in nitrogen gas decreased to extremely small values after milling for about $100 \mathrm{~h}$ and thereafter increased again concomitantly with the precipitation of the chromium nitride. In Fig. 4(b) are plotted $2 \theta$ values for the peak positions of the broad maximum and (110) reflections from the b.c.c. phase as a function of milling time. The $2 \theta$ values shifted to lower angles with increasing milling time until about $100 \mathrm{~h}$, and thereafter remained approximately constant, in spite of increasing nitrogen concentrations in the powders. The initial change may be ascribed to the lattice expansion due to the dissolution of nitrogen atoms in the b.c.c. phase, and the subsequent constancy to the precipitation of excess nitrogen as chromium nitride.

In order to examine whether the high chromium alloys milled for $100 \mathrm{~h}$ in nitrogen gas were truly amorphized, the (110) lattice image of the b.c.c. phase was observed by HRTEM for $\mathrm{Fe}_{50} \mathrm{Cr}_{50}$ powders milled for different times. As shown in Fig. 5, the grain size was progressively refined by milling and after $100 \mathrm{~h}$ milling the structure had been extremely refined to an average grain size of about $2 \mathrm{~nm}$. Noticeably, even after $100 \mathrm{~h}$ milling, when the amorphous-like pattern appeared in the structure factor, the lattice image was clearly visible and selected area electron-diffraction revealed that the b.c.c. lattice was still preserved (Fig. 5(b)). There is the possibility that the structure might have changed during the observation under the influence of electron irradiation. In order to check this point, electron diffraction patterns were carefully examined during observation at 100 and $200 \mathrm{kV}$ acceleration voltages. However, no signs of structure changes were observed. Also, the lattice expansion measured by electron-diffraction, which was $1.1 \%$ after $100 \mathrm{~h}$ milling, was approximately equal to that estimated by X-ray diffraction. It was therefore concluded that the structure was actually a nanocrystalline one with an average grain size of about $2 \mathrm{~nm}$, despite

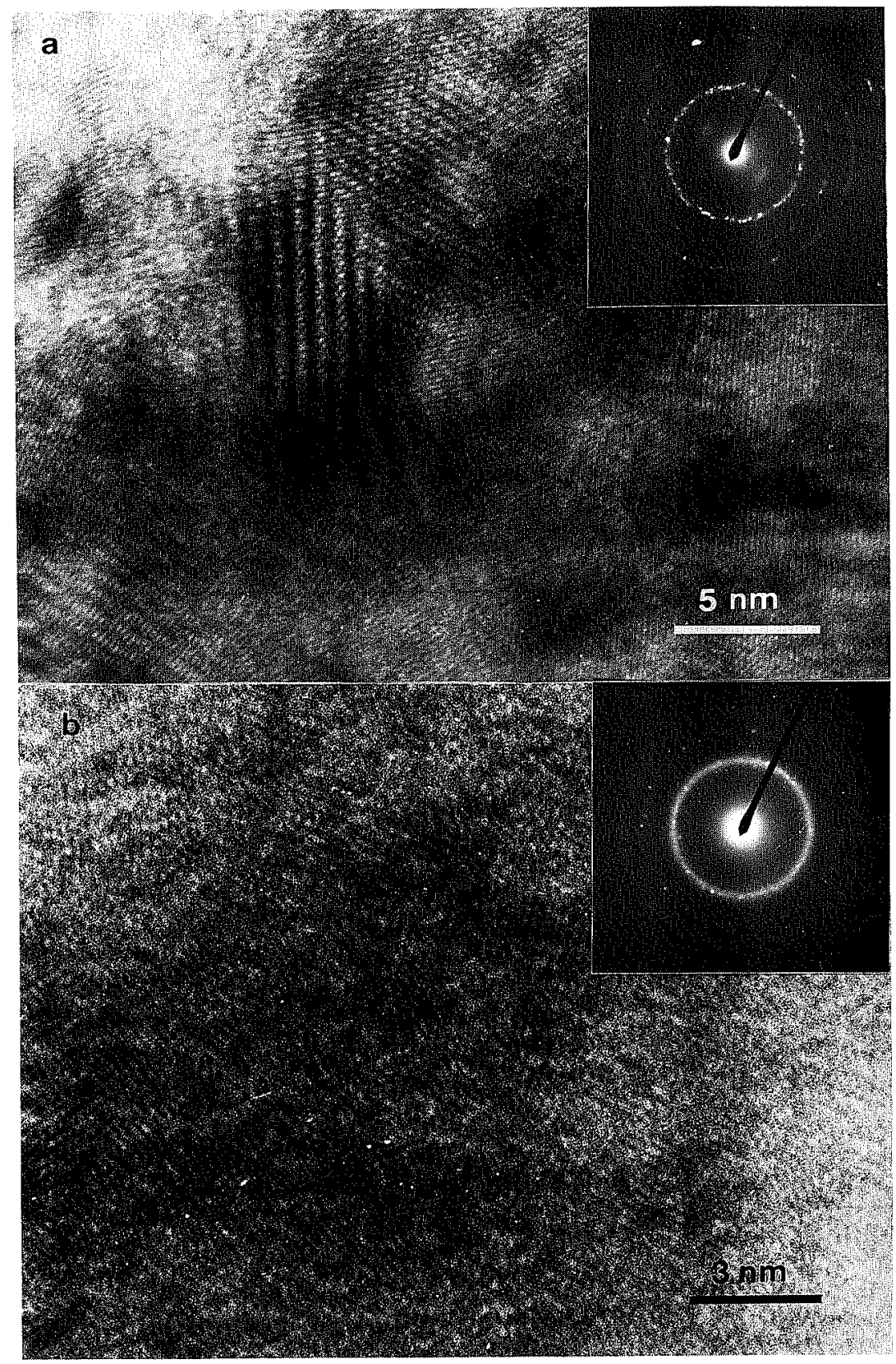

Fig. 5.

HRTEM micrographs and selected-area diffraction patterns of $\mathrm{Fe}_{50} \mathrm{Cr}_{50}$ powders milled for (a) 25 and (b) $100 \mathrm{~h}$ in nitrogen gas. 


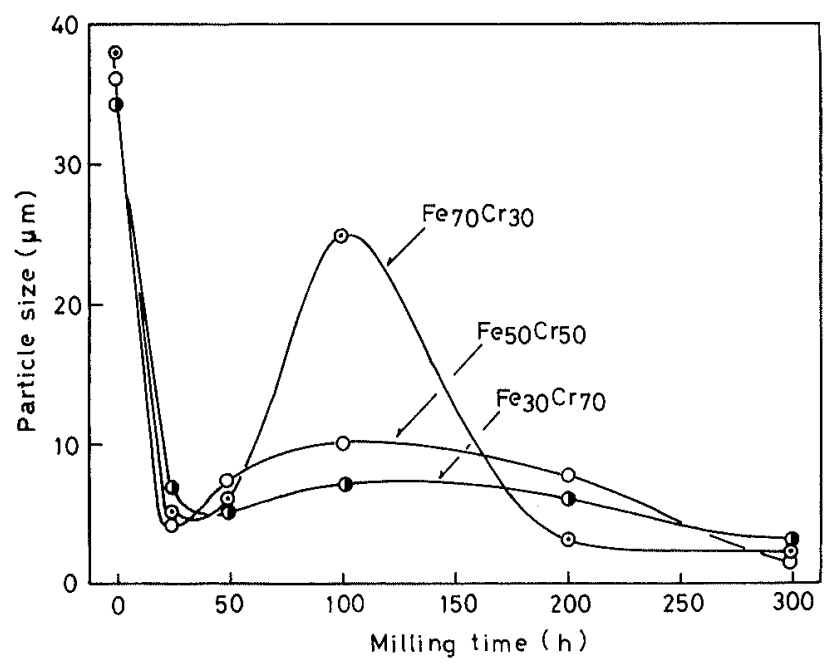

Fig. 6. Average size of powder particles milled in nitrogen gas, plotted as a function of milling time.

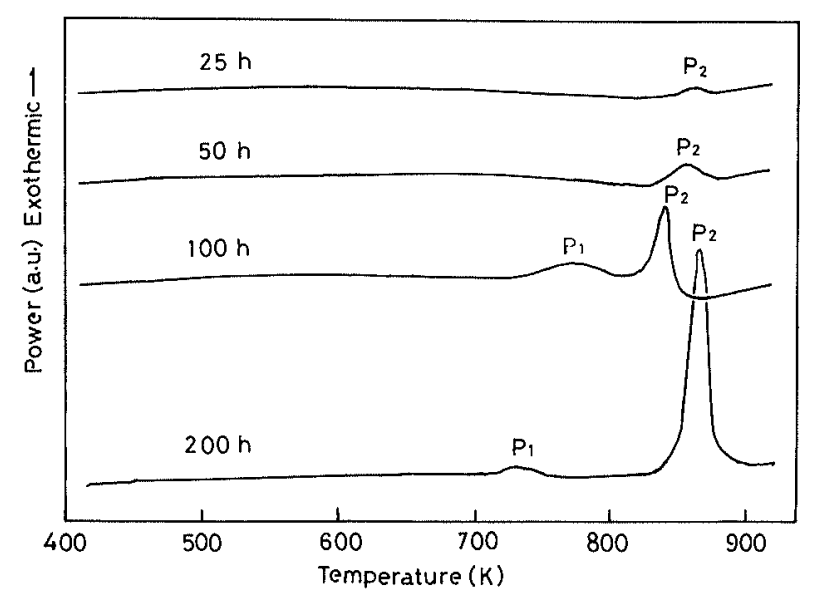

Fig. 7. DSC traces of $\mathrm{Fe}_{50} \mathrm{Cr}_{50}$ powders milled for several hours in nitrogen gas.

the appearance of an amorphous-like pattern in X-ray diffraction.

In Fig. 6 are shown particle sizes of $\mathrm{Fe}-\mathrm{Cr}$ powders milled in nitrogen gas, which were measured on SEM micrographs. Average diameters of the powder particles decreased to about $5 \mu \mathrm{m}$ after milling for $25 \mathrm{~h}$, and then increased to maximum values by milling for $100 \mathrm{~h}$, when grain sizes decreased to minimum values (Fig. 4(a)). Especially in the $\mathrm{Fe}_{70} \mathrm{Cr}_{30}$ powder, the powder agglomerated to a very large size by milling for $100 \mathrm{~h}$. Ball milling proceeds through fracture and rewelding of powder particles, and the particle size will be determined by a balance of both processes. The above fact suggests, therefore, that the cold welding of powder particles is significantly enhanced by the extreme reduction in grain size.

\subsection{Thermal Analysis}

Figure 7 shows DSC traces for the $\mathrm{Fe}_{50} \mathrm{Cr}_{50}$ powder milled for several hours in nitrogen gas. Two exothermic peaks, $\mathrm{P}_{1}$ and $\mathrm{P}_{2}$, appeared on the DCS traces. The heat evolved at $\mathrm{P}_{2}$ increased with increasing nitrogen content in the powder. X-ray diffraction patterns shown in Fig. 8 revealed that recrystallization occurred in the b.c.c.

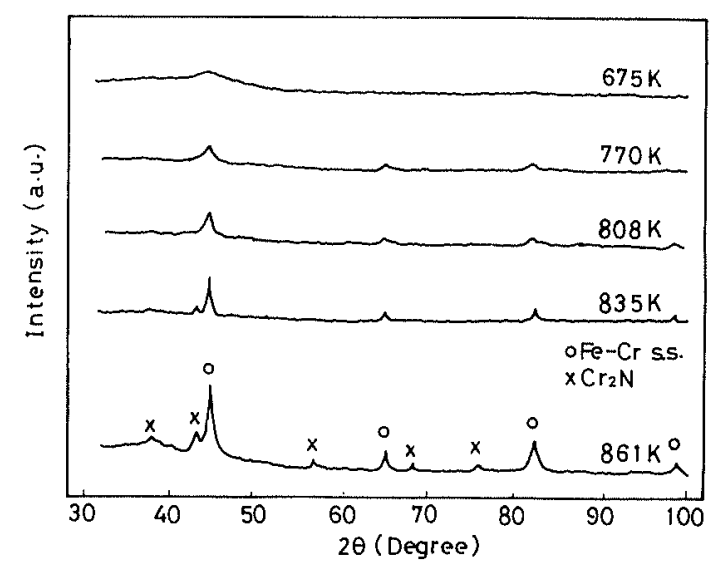

Fig. 8. X-ray diffraction patterns of $\mathrm{Fe}_{50} \mathrm{Cr}_{50}$ powders heated to several different temperatures after $100 \mathrm{~h}$ milling in nitrogen gas.

phase at temperatures around $\mathrm{P}_{1}$. At temperatures around $\mathrm{P}_{2}$, diffraction lines of a hexagonal nitride $\left(\mathrm{Cr}_{2} \mathrm{~N}\right)$ appeared. Therefore, the large heat evolution at $P_{2}$ should be due to the precipitation of the nitride. The heat evolution due to the precipitation of nitride was observed at temperatures around $850 \mathrm{~K}$ in all the alloys milled in nitrogen gas.

\subsection{Mössbauer Analysis}

Figures 9(a) to 9(d) show the Mössbauer spectra of $\mathrm{Fe}-\mathrm{Cr}$ powders milled in argon or nitrogen gas. With the $\mathrm{Fe}_{50} \mathrm{Cr}_{50}$ powders milled for 50 and $100 \mathrm{~h}$ in argon gas, the spectra revealed that they were ferromagnetic with an internal magnetic field of $13.5 \mathrm{MA} \mathrm{m}^{-1}$ (Fig. 9(a)). This value of internal magnetic field is approximately the same as that of an homogeneous $\mathrm{Fe}_{50} \mathrm{Cr}_{50}$ solid solution prepared by melting. ${ }^{5)}$ It is apparent therefore that homogeneous solid solution has been formed by milling for $50 \mathrm{~h}$ in argon gas. When milled in nitrogen gas (Fig. 9(b)), the $\mathrm{Fe}_{50} \mathrm{Cr}_{50}$ powder became paramagnetic after the absorption of about 6 and 12 at $\%$ of nitrogen by milling for 50 and $100 \mathrm{~h}$, respectively. The paramagnetism was still preserved at $4.2 \mathrm{~K}$ (Fig. 9(c)). On further milling for over $100 \mathrm{~h}$, ferromagnetic components appeared, while the paramagnetic one decreased, as shown in Fig. 9(b) by decomposing the spectrum into each component. This corresponded to the occurrence of grain growth in the b.c.c. phase and the precipitation of the nitride phase as observed in the $\mathrm{X}$ ray analysis. With the $\mathrm{Fe}_{70} \mathrm{Cr}_{30}$ powders milled for 50 and $100 \mathrm{~h}$ in nitrogen gas, the spectrum was composed of a paramagnetic peak and six ferromagnetic peaks as shown in Fig. 9(d). The internal magnetic field of the ferromagnetic component was 20.5 and $19.5 \mathrm{MA} \mathrm{m}^{-1}$ for 50 and $100 \mathrm{~h}$ milling, respectively. If the effect of dissolved nitrogen on the internal magnetic field is disregarded, the chromium concentration in the ferromagnetic component can be estimated from a relationship between the composition and the internal magnetic field of $\mathrm{Fe}-\mathrm{Cr}$ alloys. ${ }^{5)}$ The values were 29 and 33 at $\% \mathrm{Cr}$ for 50 and $100 \mathrm{~h}$ milling, respectively, which were close to the original composition of the powder. It appears therefore that the chromium concentration is approximately the 


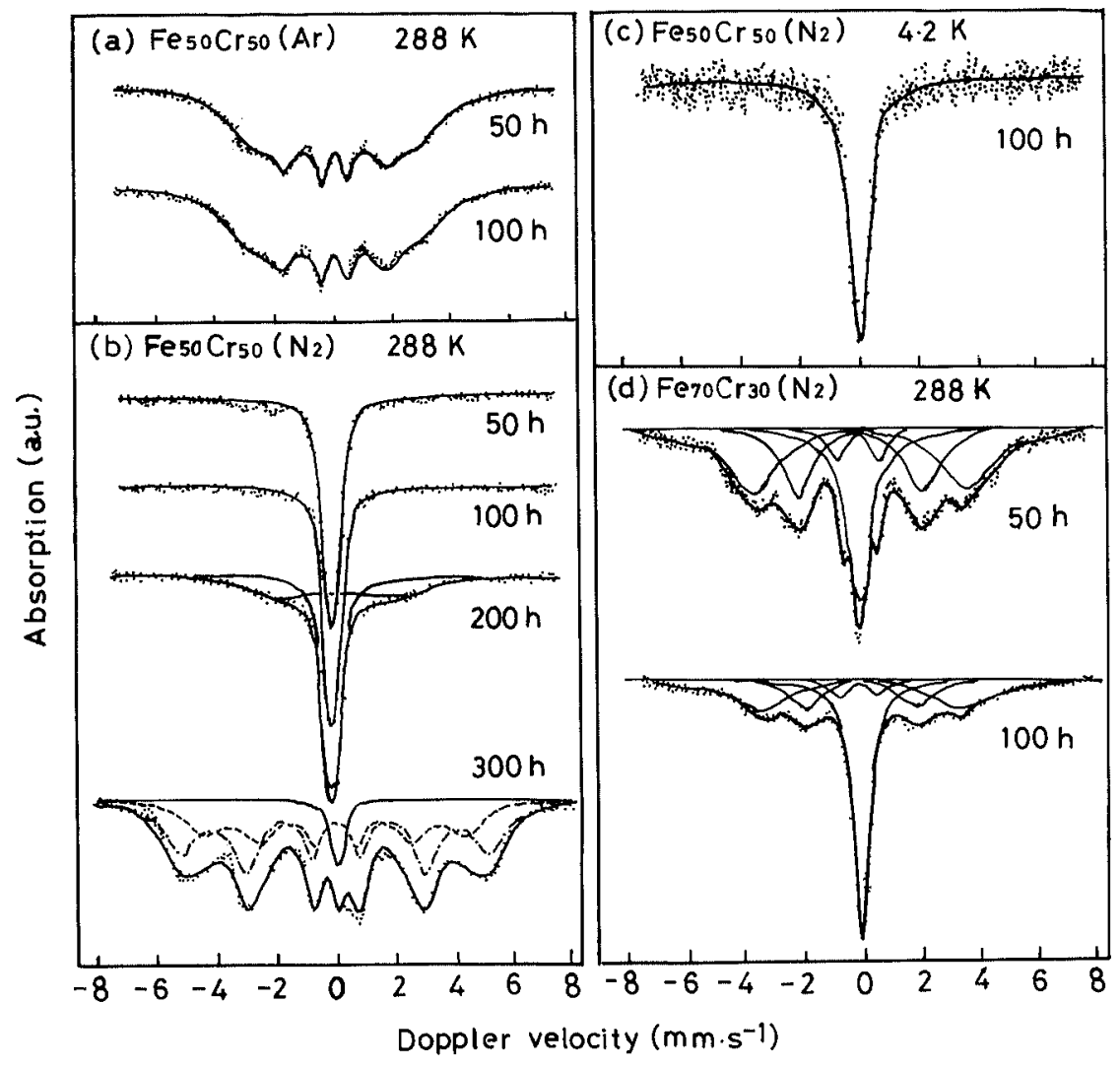

Fig. 9.

Mössbauer spectra of $\mathrm{Fe}_{50} \mathrm{Cr}_{50}$ and $\mathrm{Fe}_{70} \mathrm{Cr}_{30}$ powders milled for several hours in nitrogen and argon gases, measured at 288 and $4.2 \mathrm{k}$.

same in the paramagnetic and the ferromagnetic components.

\section{Discussion}

The present experiments have shown that the structure factor took on an amorphous-like pattern when the structure was extremely refined. With respect to this fact, a theoretical calculation made by Hamada and Fujita ${ }^{6)}$ for the structure factor of amorphous metals must be referred to. In their microcrystalline model, the amorphous state has been considered as an assembly of embryos having b.c.c. or f.c.c. structure. Each embryo includes 50 atoms and is surrounded by disordered boundaries. They have shown that the structure factor calculated from their b.c.c. model is in good agreement with experimental ones. The structure factor obtained in the present experiment is also quite similar in shape to their calculated one. The majority of grain sizes observed in the $\mathrm{Fe}_{50} \mathrm{Cr}_{50}$ powder milled for $100 \mathrm{~h}$ were smaller than $2 \mathrm{~nm}$. So, if the grain size and the grain boundary thickness are assumed to be $1.6 \mathrm{~nm}$ and two atomic spacings, respectively, the number of metal atoms in each crystallite is calculated to be about 50 atoms, which is the same as in the microcrystalline model. Therefore, if we stand on the microcrystalline model, the structure may be categorized as an amorphous one. In the present study, however, the structure will be referred to as nanocrystalline one, since it seems appropriate to distinguish the structure from the amorphous one having essentially random arrangement of atoms.

On the other hand, $\alpha$-iron and liquid iron have positive heats of solution for nitrogen, whereas solid and liquid chromium has a positive and a large negative heat of

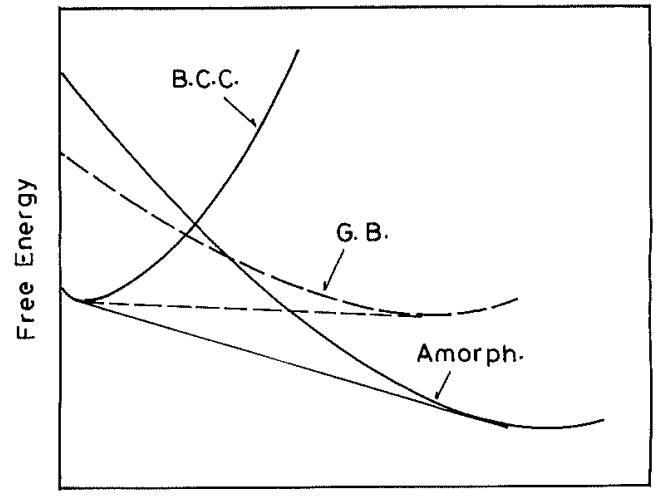

$\mathbf{N}$ content

Fig. 10. Schematic representation of free energy vs. composition relationships at the milling temperature for b.c.c., amorphous and grain boundary phases in $\mathrm{Fe}_{100-x} \mathrm{Cr}_{X}-\mathrm{N}$ pseudo-binary system at high chromium concentrations.

solution for nitrogen, respectively. The heat of solution for nitrogen in the amorphous phase of $\mathrm{Fe}-\mathrm{Cr}$ alloys may become negative, as in the liquid phase, at high chromium concentrations. Therefore, the amorphous phase may be stabilized with respect to the solid solution phase as schematically illustrated by free energy relationships in Fig. 10. As it is well known, such thermodynamic stability of the amorphous phase is a necessary requirement for the amorphization by MA. ${ }^{7)}$ Although the structure observed in the present study is a nanocrystalline one, it seems that a similar thermodynamic consideration can be applied to the present case, too. Since we have previously made a similar discussion in detail for the case of $\mathrm{Cr}-\mathrm{N}$ and $\mathrm{Cr}-\mathrm{Cu}-\mathrm{N}$ systems, ${ }^{1)}$ only a brief description will be given below. 
The grain boundary phase in the high chromium alloys may be assumed to have a large negative heat of solution for nitrogen, because the strain energy caused by the presence of nitrogen atoms should be substantially reduced at grain boundaries, as it happens in the amorphous phase. Therefore, the grain boundary phase may be stabilized with respect to the crystalline phase at high chromium and nitrogen concentrations, as illustrated by a broken line in Fig. 10. Such a free energy relationship means that the grain refinement in the high chromium alloys supersaturated with nitrogen accompanies a reduction in free energy of the system. Of course, in general grain size is reduced during MA. The thermodynamic driving energy, however, will promote the grain refinement and the grain size will be progressively refined to extremely small sizes under the steady supply of nitrogen atoms as observed in the present study. It is proposed, therefore, that the nanocrystalline structure of the high chromium alloys was produced as a result of the stabilization of grain boundaries by the presence of a large amount of nitrogen.

With respect to the magnetic properties of the alloys, the partition of nitrogen atoms between grain boundaries and lattice sites must be taken into account. Nitrogen may be segregated on grain boundaries, since they have a high tendency to segregate in the alloys and have a sufficient mobility for the segregation to occur at the milling temperature. In the case of $\mathrm{Fe}_{70} \mathrm{Cr}_{30}$ powders milled in nitrogen gas, the proportion of iron atoms present in the paramagnetic component can be evaluated from the area of each component in the Mössbauer spectrum. The values are 31 and 45 at $\%$ for 50 and $100 \mathrm{~h}$ milling, respectively. The grain sizes of the alloy, which were roughly estimated from X-ray analysis, were 5.5 and $5 \mathrm{~nm}$ for 50 and $100 \mathrm{~h}$ milling, respectively. If three atomic spacings are assumed for the grain boundary thickness, the proportion of the metal atoms present in grain boundaries is calculated to be 30, 40 and 50 at $\%$ for grains which are 6,5 and $4 \mathrm{~nm}$ in diameter, respectively. These proportions are comparable to those in the paramagnetic component. Therefore, it seems likely that the paramagnetism arises from the grain boundaries where nitrogen atoms are enriched. In the $\mathrm{Fe}_{50} \mathrm{Cr}_{50}$ powders milled for 50 and $100 \mathrm{~h}$ in nitrogen gas, it appears that the alloys are entirely paramagnetic both at grain boundaries and inside the grains. It must be noted that the Mössbauer spectrum takes on a similar pattern in both the alloys irrespective of the difference in the structure factors (Fig. 3). This is consistent with the observation that the structure is composed of nanometersized b.c.c. grains even when the structure factor exhibits the amorphous-like pattern. The nitrogen concentrations inside the grains may be lower than average concentrations, which are about 6 and 12 at $\%$ for 50 and $100 \mathrm{~h}$ milling respectively, because of the segregation on grain boundaries. The grain sizes are about 5 and $2 \mathrm{~nm}$ after milling for 50 and $100 \mathrm{~h}$, respectively. For such nanometer-sized grains surrounded by paramagnetic grain boundaries, the appearance of superparamagnetism may be expected. However, this may not be the case because the paramagnetism is still preserved at $4.2 \mathrm{~K}$, where the cooperative thermal fluctuations of electron spins may be frozen.

Further detailed studies which are required for understanding the magnetic properties of the alloys are now in progress.

\section{Conclusions}

By ball-milling $\mathrm{Fe}_{100-x} \mathrm{Cr}_{X}(X=0,30,50$ and 70$)$ mixtures of powdered elements in nitrogen gas, $\mathrm{Fe}-\mathrm{Cr}-\mathrm{N}$ alloys with very high concentrations of nitrogen can be prepared. The nitrogen concentration of the alloy milled for a given time increases with increasing chromium concentration in the alloy in the composition range up to 50 at $\% \mathrm{Cr}$. The structure of the nitrided powders consists of nanometer-sized grains of b.c.c. solid solution supersaturated with nitrogen. For the $\mathrm{Fe}_{50} \mathrm{Cr}_{50}$ powder milled for $100 \mathrm{~h}$, the structure factor calculated from $\mathrm{X}$-ray diffraction exhibits an amorphous-like pattern, while the structure is still composed of extremely fine b.c.c. grains as observed by HRTEM. By milling for longer than about $100 \mathrm{~h}$, a nitride phase precipitates in all the $\mathrm{Fe}-\mathrm{Cr}$ alloys, and concomitantly grain growth occurs in the b.c.c. phase. On annealing the nitrided powders, the precipitation of $\mathrm{Cr}_{2} \mathrm{~N}$ phase occurs at temperatures around $850 \mathrm{~K}$ accompanied by a heat evolution.

The nitrided $\mathrm{Fe}_{70} \mathrm{Cr}_{30}$ alloy has a magnetic structure consisting of paramagnetic and ferromagnetic components as revealed by Mössbauer spectroscopy. As the chromium concentration increases to 50 at $\%$, the nitrided alloy becomes entirely paramagnetic after a reduction in grain size below about $5 \mathrm{~nm}$ during milling.

\section{Acknowledgement}

The authors gratefully acknowledge the financial support of the Iron and Steel Institute of Japan for this work.

\section{REFERENCES}

1) Y. Ogino, S. Murayama and T. Yamasaki: J. Less-Common Met., 168 (1991), 221.

2) Y. Ogino, M. Miki, T. Yamasaki and T. Inuma: Mater. Sci. Forum, 88-90 (1992), 795.

3) A. Calka and J. S. Williums: Mater. Sci. Form, 88-90 (1992), 787.

4) S. Saji, K. Matsumoto, T. Shibayanagi, T. Yamasaki, Y. Ogino and T. Sakata: J. Jpn. Inst. Met., 56 (1992), 509.

5) H. Kuwano and Y. Morooka: J. Jpn. Inst. Met., 8 (1980), 202.

6) T. Hamada and F. E. Fujita: Proc. 4th Int. Conf. on Rapidly Quenched Metals, Sendai, (1981), 73.

7) L. Schultz: Mater. Sci. Eng., 97 (1988), 15. 